\title{
Queratitis fúngica: revisión actual sobre diagnóstico y tratamiento
}

\author{
Fungal keratitis: review of diagnosis and treament
}

Felipe Mellado ${ }^{1}$, Tomás Rojas ${ }^{1}$, Cristián Cumsille ${ }^{1}$

\section{RESUMEN}

La queratitis fúngica es una infección característica de zonas tropicales, asociada a trauma vegetal. Existen dudas respecto al método diagnóstico óptimo y la efectividad de los tratamientos disponibles. ¿Cuál es el manejo más apropiado en queratitis fúngica? y ¿Cuál es la mejor forma de establecer el diagnóstico? El cultivo para hongos es el gold standard diagnóstico de elementos fúngicos. Respecto al tratamiento, natamicina y anfotericina B fueron los más utilizados y no demostraron efectividad en estudios prospectivos. Voriconazol demostró efectividad en múltiples infecciones fúngicas. Pudiera ser la droga de elección en condiciones óptimas, dado su mejor penetración intraocular. Se ha reconocido su elevado costo dificultando su aplicación generalizada. Esta revisión entrega recomendaciones para el manejo y establece la necesidad de realizar estudios que evalúen la costo-efectividad de voriconazol para la queratitis fúngica.

Descriptores: Queratitis/diagnóstico; Queratitis/microbiologia; Queratitis/quimioterapia; Cornea/microbiologia; Infecciones fúngicas del ojo; Itraconazol/uso terapéutico; Anfotericina B/uso terapéutico; Antifúngicos

\begin{abstract}
Fungal keratitis is a characteristic infection upon tropical zones, associated with vegetal trauma. Doubt exists about the best diagnostic test and the effectiveness of available treatment. Which is the best diagnostic method for fungal keratitis? And, which is the best management? Fungal culture remains as diagnostic gold standard of fungal elements. As of treatment, natamycin and amphotericin B are the most popular drugs for fungal keratitis and they have not shown effectiveness in randomized controlled trials or systematic reviews. Voriconazole showed effectiveness and security in multiple fungal infections. It may be the drug of choice in optimal conditions, because of its better ocular penetration and wider coverage. However, its high price difficult general application. This review establishes management recommendations and the need to perform studies that address cost-effectiveness analysis of voriconazole for fungal keratitis.
\end{abstract}

Keywords: Keratitis/diagnosis; Keratitis/microbiology; Keratitis/drug therapy; Cornea/ microbiology; Eye infections, fungal; Itraconazole/therapeutic use; Amphotericin B/ therapeutic use; Antifungal agents

\section{INTRODUCCIÓN}

Actualmente la queratitis infecciosa se mantiene como una de las causas más prevalentes de ceguera no reversible a nivel mundial, según datos de la $\mathrm{OMS}^{(1)}$. Las principales causas de la queratitis infecciosa varían enormemente según la región geográfica, el nivel socioeconómico, la presencia de factores de riesgo como el uso de lentes de contacto, historia de trauma ocular, comorbilidades y edad del paciente ${ }^{(2)}$. Dentro de la etiología de la queratitis infecciosa, la infección corneal por hongos varía entre un 6 y un $60 \%$ dependiendo de la región geográfica que se exponga ${ }^{(3-6)}$. Tradicionalmente se describe a esta entidad como una afección oportunista de zonas tropicales y rurales, causada mayoritariamente por trauma con exposición vegetal. Sin embargo, en países desarrollados su causa sería principalmente secundaria al uso de lentes de contacto ${ }^{(7)}$. Los estudios microbiológicos exponen que la queratitis fúngica es producida fundamentalmente por hongos filamentosos y levaduras ${ }^{(8)}$. Los estudios realizados en Sudamérica muestran que los hongos filamentosos afectarían con mayor frecuencia, siendo Fusarium y Aspergillus las principales etiologías $(2,9,10)$. El principal factor de riesgo asociado a infecciones por hongos filamentosos es el trauma vegetal. Respecto a las levaduras, Candida es la que afecta con mayor frecuencia y se presenta mayormente cuando existe compromiso de la superficie corneal como en córneas neurotróficas, usuarios de corticoides tópicos crónicos o luego de procedimientos quirúrgicos ${ }^{(11)}$. El diagnóstico de la querati- tis fúngica es difícil y debe estar basado en la clínica y el laboratorio. Los hallazgos oculares más frecuentes al examen oftalmológico son compromiso epitelial y estromal, sin embargo se documentan casos de compromiso endotelial y de cámara anterior sin daño corneal previo(12). La queratitis fúngica es una entidad de tratamiento complejo, requiere antifúngicos por tiempo prolongado y debridaciones frecuentes ${ }^{(13)}$. Presenta un peor pronóstico visual que las queratitis bacterianas, probablemente explicado por la carencia de tratamientos efectivos, requiriendo más injertos corneales y enucleaciones ${ }^{(14)}$. Clásicamente los tratamientos más utilizados han sido natamicina tópica para hongos filamentosos y anfotericina B para levaduras ${ }^{(15)}$. Sin embargo persisten dudas respecto al mejor esquema de tratamiento actual, principalmente dado la escasa penetración intraocular de los antifúngicos mencionados ${ }^{(14)}$. La rareza de esta patología, la falta de terapias efectivas que se encuentren disponibles para países en vías de desarrollo, sumado a la escasez de estudios locales de esta condición, generan un gran desafío para el médico oftalmólogo y dan cuenta de la necesidad de realizar una revisión actualizada de las terapias disponibles, basado en evidencia y con recomendaciones claras para un mejor enfrentamiento de esta afección.

Esta revisión pretende contestar las dos siguientes preguntas: ¿Cuál es el manejo más apropiado para la queratitis por hongos? y ¿Cuál es la mejor forma de realizar el diagnóstico?, entregando recomendaciones claras y adaptadas a nuestro medio para el enfrentamiento en la práctica clínica. 


\section{MÉTODOS}

Se realizó una búsqueda acabada en las principales bases de datos MEDLINE, Cochrane Library, EMBASE, CINAHL, SCISEARCH, EPISTEMONIKOS, LILACS, con términos específicos "microbiology" [MeSH Terms] OR"fungi" [MeSH Terms] OR fungal[Text Word] and "keratitis" [MeSH Terms] OR keratomycosis [Text Word] and "Antifungal Medication" [MeSH Terms]. Se seleccionaron 15 artículos, prefiriéndose los ensayos clínicos randomizados (ECR) y revisiones sistemáticas de ECR, además se incluyeron estudios retrospectivos y cohortes históricas. Los artículos fueron seleccionados por dos revisores en forma independiente. Todos los artículos fueron revisados en idioma inglés y español.

\section{Diagnóstico}

Como se describió anteriormente, el manejo de la queratitis fúngica ofrece múltiples dificultades. Siempre debiera sospecharse una queratitis mediada por hongos en casos de queratitis que no respondan a terapia antibacteriana y que tengan como factores de riesgo un trauma con exposición vegetal o el uso extendido de lentes de contacto ${ }^{(14)}$. Existe amplia evidencia de la necesidad de un diagnóstico precoz para impartir tratamiento lo antes posible y así evitar las complicaciones que amenacen la integridad visual ${ }^{(2)}$. Si bien se han descrito ciertos elementos al examen físico que pudieran orientar a la queratitis por hongos, como un cuadro de curso indoloro en presencia de lesión corneal de márgenes irregulares en forma de pluma, asociado a lesiones satélites, de textura seca, con placas endoteliales, etc., (Figura 1) éstos no se han demostrado suficientes para establecer el diagnóstico por sí solos ${ }^{(16)}$. En la serie de Ibrahim et al. ${ }^{(17)}$, se demostró que solo el $48 \%$ de los casos de queratitis fúngica fueron correctamente identificados mediante el examen clínico. Tradicionalmente el diagnóstico se establece con una visualización directa de muestra corneal en conjunto de cultivos para hongo. En otras ocasiones se puede requerir incluso de biopsia corneal o paracentesis de cámara anterior.

\section{Visualización DIRECTA}

El frotis busca la visualización directa de formas fúngicas usando tinciones. La tinción de $\mathrm{KOH}$ al 10\% ha demostrado la mayor sensibilidad y especificidad para el diagnóstico de hongos alcanzando cifras entre 50 y 99\% para ambas medidas según la serie. Tiene como ventajas el fácil acceso y la disponibilidad en países en vías de desarrollo que a su vez son los que han reportado mayor prevalencia de queratitis fúngica. A su vez, se han buscado asociaciones con otras tinciones como Calco Flúor y Giemsa para aumentar el rendimiento(18).

\section{Cultivos para hongo}

En general se ha mantenido el cultivo para hongos como el Gold Standard para el diagnóstico de la queratitis fúngica (Figura 2). Su utilidad para identificar el microorganismo y la susceptibilidad antibiótica de éste, ha sido ampliamente reconocida(19,20). Sin embargo, tiene como desventajas el tiempo que requiere para encontrar hallazgos, ya que hasta un 25\% de los cultivos podrían hacerse positivos recién a las 3 semanas del cuadro(18), lo que retrasaría el tratamiento pudiendo otorgar un peor pronóstico. Los medios de cultivos para hongos con mejor rendimiento y más utilizados son agar sangre y Sabouraud. En un estudio de 28 ojos que fueron positivos para diagnóstico de queratitis fúngica mediante frotis directo y PCR, sólo un $68 \%$ de los cultivos resultaron positivos, lo que pudiera ser explicado dado la alta tasa de falsos negativos que se producen producto de los tratamientos previos a la toma de muestras ${ }^{(19)}$.

\section{TÉCNICAS MOLECULARES}

Durante los últimos años han surgido nuevas técnicas basadas en la biología molecular, como la reacción de polimerasa en cadena

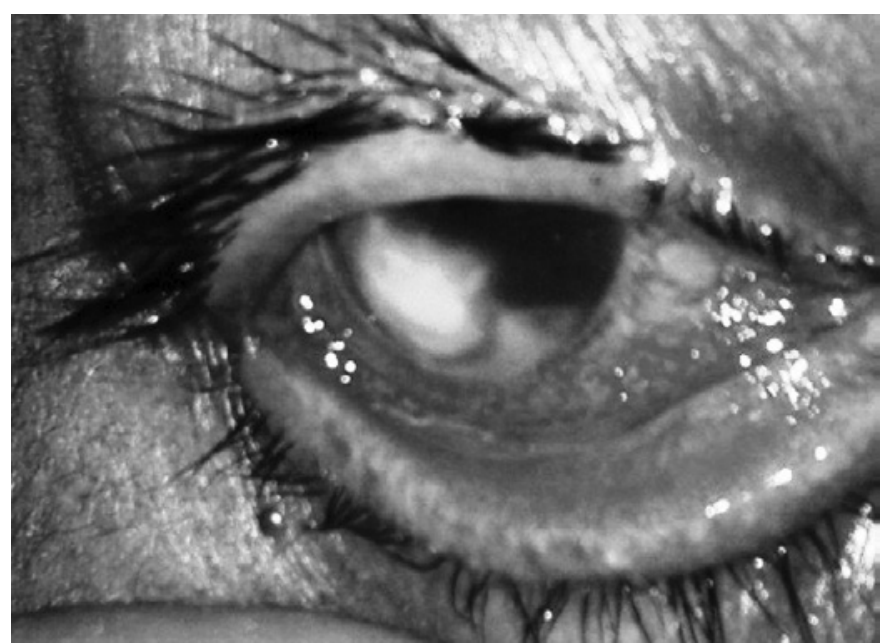

Figura 1. Cuadro clínico típico de queratitis fúngica al examen oftalmológico. Se presenta como un cuadro no doloroso de afección corneal, de bordes irregulares y lesiones satélite asociadas.

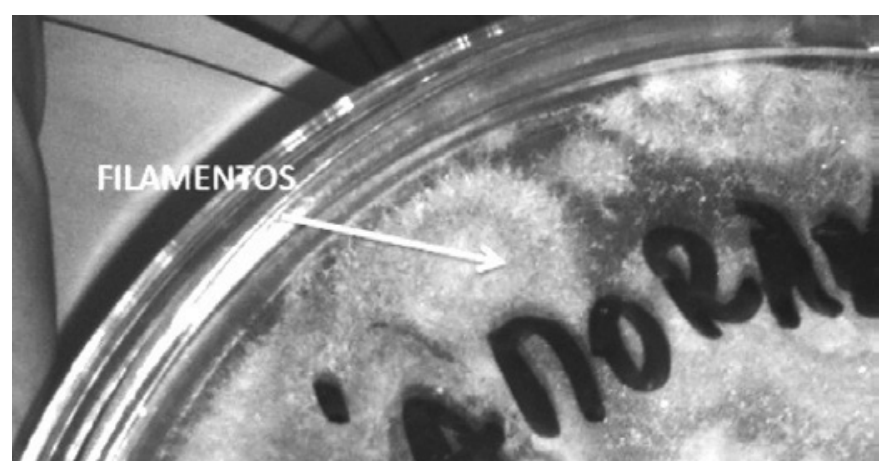

Figura 2. Cultivo para hongos (agar Saboraud) revela crecimiento de Fusarium al 5 to día.

(PCR) para detección precoz de infección fúngica. Su ventaja principal es que sólo requiere una pequeña muestra para la detección tanto de organismos viables como no viables. ${ }^{(19)}$ A su vez la PCR entrega resultados en menos de 24 horas, lo que es una ventaja respecto al cultivo en cuanto al tiempo de diagnóstico. En una evaluación prospectiva de $P C R$, utilizada para casos sugerentes de queratitis fúngica mediante clínica, se observó que un 50\% de los casos resultaron positivos con PCR, mientras que sólo un $25 \%$ de los cultivos mostró desarrollo fúngico. Es de notar en este estudio, que los ojos tratados previamente a la toma de muestras dieron $50 \%$ de positividad para PCR, comparado con sólo un $30 \%$ de positividad para los cultivos ${ }^{(21)}$. Este estudio también reportó algunos casos de cultivo positivo con resultado negativo al utilizar PCR, por lo que esta prometedora técnica molecular, sólo debiera ser utilizada de manera sinérgica al cultivo y frotis, no así como único método diagnóstico.

\section{IMÁGENES}

Lo más novedoso respecto al diagnóstico de la queratitis fúngica, son las nuevas técnicas imagenológicas mediante microscopía confocal in vivo (IVCM) ${ }^{(22,23)}$. Este sistema permite la visualización de todas las capas corneales y a su vez de componentes microbianos que pudieran estar presentes entre ellas, de manera rápida y no invasiva. Vadavalli et al. ${ }^{(23)}$, presentaron 146 casos de queratitis infecciosa (de las cuales el 98 fueron mediadas por hongos). En esta serie la IVCM tuvo una sensibilidad de $89 \%$ y una especificidad de $93 \%$ para la de- 
tección de elementos fúngicos. Todavía se requiere de mayor evidencia sistematizada para poner en práctica este método diagnóstico pero se empieza a observar una tendencia en esta dirección (Tabla 1).

\section{Tratamiento}

En el caso de diagnóstico de elementos fúngicos corneales con las técnicas recién descritas, se debe establecer terapia antifúngica lo más pronto posible. El objetivo de la terapia es evitar las complicaciones visuales de la queratitis y lograr la erradicación de la infección al examen clínico, que se demuestra al lograr la desaparición de los bordes irregulares en pluma de la lesión corneal, la disminución de reacción de cámara anterior y reepitelización corneal(18). Sin embargo, lograr lo anterior ofrece muchas dificultades. La inefectividad de los antifúngicos disponibles y la mínima penetración ocular de las terapias tópicas sumado a la capacidad de los hongos para penetrar de manera profunda en el estroma, membrana de Descemet y cámara anterior sin requerir de una irrupción previa en la superficie epitelial corneal, dificultan la resolución clínica de la infección ${ }^{(12)}$

\section{Polienos}

Tratamiento clásico de la queratitis fúngica, primer antifúngico aceptado por la Food and Drug Administration (FDA) fue la natamicina tópica al 5\%(24). Este polieno, cuyo mecanismo de acción es la unión al ergosterol de la pared celular del hongo, impide su homeostasis y provoca muerte celular por esta causa. Desde su aprobación, la natamicina se volvió el fármaco más popular para el tratamiento de hongos filamentosos. Dado su mala penetración ocular y baja tasa de tratamiento exitoso, la mayoría de los investigadores recomiendan debridaciones corneales seguidas para una mejor penetración ocular del fármaco ${ }^{(13)}$. Por su parte, la anfotericina B al 0,15\%, ha sido utilizada ampliamente para el tratamiento de infecciones por levaduras siendo fármaco de primera línea para queratitis por Candida ${ }^{(15)}$, y al igual que la natamicina, presenta problemas para atravesar la superficie corneal a través de un epitelio intacto(18).

\section{Azoles}

La familia antifúngica de los azoles, tanto imidazoles como triazoles (diferenciados en su vida media) logran su efecto inhibiendo la síntesis de ergoesterol, esencial para la pared celular y mediante este mecanismo lograrían su efecto manteniéndose clásicamente como fármacos de segunda línea en el tratamiento de la queratitis fúngica. Sin embargo, durante los últimos años el voriconazol, un derivado sintético del fluconazol, se ha convertido en una alternativa prometedora de tratamiento para esta entidad, dado su excelente penetrancia ocular y su gran espectro de cobertura fúngica(25).

\section{Eouinocandinas}

Caspofungina y micafungina son los principales representantes. Actúan inhibiendo enzimas de síntesis de membrana celular. No han demostrado efectividad sobre los tratamientos anteriores ni evidencia para su aplicación de elección en queratitis fúngica ${ }^{(18)}$.

\section{Tabla 1. Alternativas diagnósticas y sus características}

\begin{tabular}{ll}
\hline Métodos diagnósticos & \multicolumn{1}{c}{ Componentes } \\
\hline Visualización directa & $\begin{array}{l}\text { Frotis con tinción de } \mathrm{KOH} \text {, Giemsa o Blanco de Calco } \\
\text { flúor }\end{array}$ \\
Cultivos para hongos & $\begin{array}{l}\text { Cultivo para hongo en agar Sabouraud o agar sangre } \\
\text { Resultados desde 24-36 horas hasta 3 semanas }\end{array}$ \\
Técnicas moleculares & $\begin{array}{l}\text { PCR para detección precoz. Resultados en menos } \\
\text { de 24 horas }\end{array}$ \\
Imágenes & Microscopia confocal in vivo \\
\hline
\end{tabular}

\section{TERAPIA ANTIFÚNGICA SISTÉMICA}

En aquellos casos de queratitis fúngica más severos, que se presentan o evolucionan con úlceras grandes, hipopion y/o compromiso de cámara anterior, se recomienda utilizar terapia antifúngica sistémica adyuvante, aún cuando no ha demostrado un claro beneficio en ensayos clínicos randomizados llevados a cabo ${ }^{(26)}$. La anfotericina B se ha usado ampliamente para el tratamiento de endoftalmitis fúngica, tanto EV como con inyecciones intravítreas, con limitación de cobertura micótica y conocidos efectos adversos de toxicidad retinal e inflamación ocular ${ }^{(14,27)}$. Por su parte, el fluconazol vía oral tiene claro efecto en la infección por Candida, no así en hongos filamentosos que se describen como principal causa de queratitis fúngica ${ }^{(28)}$, limitando así su uso como primera línea. Itraconazol oral ha sido poco utilizado en infecciones fúngicas oculares dado su pobre espectro de acción, especialmente contra Fusarium, sin embargo se ha reportado útil para infecciones por Aspergillus y ha sido considerado recientemente terapia convencional(27). Durante los últimos años, voriconazol oral ha demostrado efectividad y seguridad en múltiples infecciones por hongos. Presenta un mayor espectro de acción, mejor susceptibilidad in vitro y menores concentraciones inhibitorias mínimas (CIM) para Candida y Aspergillus, que los antifúngicos previamente mencionados ${ }^{(29)}$. Sólo se ha realizado un ECR comparando voriconazol tópico y oral versus terapia antifúngica convencional (natamicina 5\% + itraconazol oral). Este estudio concluye que voriconazol podría ofrecer mayor eficacia sobre el tratamiento convencional, especialmente en queratitis por Aspergillus (27). En casos de compromiso de cámara anterior secundario a queratitis por Candida, se ha recomendado iniciar terapia antifúngica intracameral con anfotericina B o voriconazol como primera línea ${ }^{(30,31)}$. Se han explorado otras formas de tratamiento como inyecciones intracorneales o subconjuntivales, las que se reportan dolorosas y susceptibles de efectos adversos severos como la necrosis epitelial conjuntival(32). La carencia de evidencia de calidad no permite recomendarlas como tratamiento actualmente ${ }^{(33)}$.

\section{Cirugía}

Cuando el tratamiento médico máximo no obtiene resultados - la infección clínica es muy grave, se debe realizar manejo quirúrgico. Entre las técnicas utilizadas encontramos el flap conjuntival, la adhesión de superficie ocular y la queratoplastia lamelar. Si bien el flap conjuntival aumentaría la llegada de células inmunocompetentes para la reparación del tejido corneal, podría actuar como barrera para los antifúngicos tópicos sumado a la incapacidad de observar la evolución de la lesión ${ }^{(34)}$. A su vez la queratoplastía lamelar no sería útil dado la capacidad de los hongos de penetrar en capas profundas lo que explicaría la falla terapéutica de abordaje quirúrgico ${ }^{(35)}$. Sin embargo la técnica de excelencia es la queratoplastia terapéutica penetrante, que corresponde a la extracción del tejido corneal infectado y reemplazado mediante un transplante de córnea ${ }^{(33)}$. Se ha reportado que hasta un 30\% de las queratitis fúngicas se resuelven mediante queratoplastia penetrante ${ }^{(36)}$. Cabe destacar que aun cuando los casos de queratitis fúngicas documentadas son poco comunes, dan cuenta de la mitad de las queratoplastías penetrantes que se realizan por queratitis infecciosas ${ }^{(37)}$. A su vez se ha descrito que la tasa de éxito quirúrgico es peor en pacientes con queratitis fúngica, independiente de la tasa de erradicación, el éxito anatómico o la claridad del injerto, y que pesar de este tratamiento quirúrgico, cerca de un 7\% de los casos presentan recurrencia de la infección ${ }^{(33)}$. Es por esto que en los últimos años se han proyectado nuevas formas de abordaje quirúrgico basadas en UV-A uniones de colágeno y riboflavina ${ }^{(38)}$, que representan alternativas de investigación novedosas para el tratamiento de esta patología, pero que carecen de evidencia sistematizada que las soporte actualmente (Tabla 2). 


\section{DISCUSIÓn}

En esta revisión se encontraron 3 revisiones sistemáticas que abordaron el tratamiento médico antibiótico para esta patología. En la Revisión Cochrane $2008^{(39)}$, se concluyó que tanto la natamicina al $5 \%$ como todos los medicamentos evaluados fueron inefectivos en el tratamiento de la queratitis fúngica, evidenciándose la necesidad de realizar nuevos estudios clínicos aleatorizados de terapia. Sin embargo, ninguno de los estudios evaluados en dicha revisión sistemática utilizó anfotericina B ni voriconazol. A su vez se han realizado múltiples ensayos clínicos aleatorizados que compararon anfotericina B y voriconazol, que no pudieron demostrar diferencias significativas entre ambos fármacos ${ }^{(40-42)}$. En la serie publicada por Hariprasad et al. ${ }^{(25)}$, se evaluaron cerca de 40 casos clínicos de queratitis fúngica en los que se administró voriconazol oral y tópico, concluyéndose que es un medicamento que podría usarse de manera segura y efectiva para múltiples infecciones por hongos. En una encuesta de práctica clínica realizada por The Cornea Society a nivel mundial, los oftalmólogos entrevistados eligieron voriconazol, sobre natamicina, como terapia de elección para la queratitis fúngica en un mundo ideal ${ }^{(15)}$. Cabe recordar que el voriconazol oral es muy costoso, lo que es una desventaja en su implementación, a pesar de su efectividad. A su vez, este medicamento es metabolizado a través del sistema de citocromos p450, por lo que se debiera tener precaución especial con pacientes bajo terapia anticoagulante.

\section{CONCLUSIÓN Y RECOMENDACIONES}

La queratitis fúngica es una entidad poco común dentro de las queratitis infecciosas. Los estudios han señalado que su manejo es complejo. Una vez confirmado el diagnóstico, o teniendo sugerencia del éste, debe instaurarse tratamiento antibiótico inmediato cubriendo al microorganismo de sospecha. En esta revisión se ha planteado que la sospecha diagnóstica es eminentemente clínica, sugerida por las lesiones características de la queratomicosis al examen clínico. Sin embargo dado la baja sensibilidad del examen clínico como único elemento diagnóstico, deben realizarse estudios de laboratorio complementarios que identifiquen el tipo de hongo y definan su susceptibilidad frente al antifúngico. Los estudios diagnósticos a realizar debieran incluir un frotis de $\mathrm{KOH}$ junto a cultivo para hongos en agar Sabouraud, en todo paciente en que se sospeche una queratitis fúngica al examen con lámpara de hendidura. Luego de la toma de muestras, se debe comenzar con un régimen antifúngico precoz. Si bien la natamicina tópica al 0,5\% es el fármaco más disponible, no

Tabla 2. Alternativas terapéuticas y objetivos

\begin{tabular}{ll}
\hline Tratamiento & \multicolumn{1}{c}{ Objetivo } \\
\hline $\begin{array}{l}\text { Polienos tópicos } \\
\text { (Natamicina y anfotericina B) }\end{array}$ & - -Anfotericina en caso de aislar levaduras \\
Azoles tópicos & -Voriconazol tópico de elección tanto para hongos \\
(Voriconazol, itraconazol) & filamentosos o levaduras y en caso de agente \\
& desconocido dado su amplio espectro \\
& -Itraconazol tópico sin evidencia que lo sustente \\
Terapia sistémica & -Voriconazol oral es de elección, indicado en \\
(Oral, E.V., intracameral, & falla a tratamiento tópico, en caso de úlceras \\
subconjuntival) & corneales centralesy profundas al diagnósticoyen \\
& compromiso de cámara anterior. Es primera línea \\
& para hongos filamentosos y levaduras \\
& -Inyeccion intracamerales en caso de levaduras \\
& aisladas y como segunda línea \\
& -Itraconazol oral segunda línea para hongos \\
& filamentosos \\
& -Queratoplastía penetrante es de elección en caso \\
& de falla a tratamiento médico máximo y en casos \\
de perforación corneal inminente
\end{tabular}

ha sido capaz de demostrar su efectividad para el tratamiento de la queratomicosis en ensayos clínicos aleatorizados ni revisiones sistemáticas llevadas a cabo. Por esta razón, en casos sugerentes de queratitis fúngica en los que el microorganismo no ha sido identificado, la literatura actual recomienda iniciar terapia antimicótica biasociada, con un régimen basado en anfotericina $\mathrm{B}$ al 0,15\% y/o voriconazol tópico 1\% dado su mejor espectro de cobertura. En países en vías de desarrollo, la disponibilidad de voriconazol tópico u oral es mínima, por lo que debieran buscarse alternativas basadas en anfotericina B tópica al 0,15\% como fármaco de elección. Sin embargo, al no comercializarse preparado, se debe solicitar su composición al laboratorio lo que pudiera resultar engorroso para su aplicación generalizada. Inicialmente, e independiente del fármaco utilizado, se recomienda administrar el antifúngico cada 1 hora acompañado de debridaciones cada 3 días (Tabla 3). El tiempo de tratamiento no está claro, se ha descrito que en promedio se requiere de 80 días para la erradicación de la infección al examen clínico. Cuando el paciente se presenta con úlceras grandes, centrales, profundas, con placas endoteliales, compromiso de cámara anterior y/o hipopion, se recomienda establecer terapia antifúngica sistémica de manera coadyuvante al tratamiento tópico y derivación a oftalmólogo especialista en córnea durante el mismo día (Tabla 4). Si la infección no responde al tratamiento médico máximo, con aumento de reacción en cámara anterior, sospecha de perforación corneal o compromiso de segmento posterior, el tratamiento quirúrgico estaría indicado. El procedimiento de elección es la queratoplastia terapéutica penetrante, sin embargo puede llegar a realizarse enucleación en los casos más severos. Debido a que la queratomicosis puede tener como secuela la pérdida de agudeza visual o incluso pérdida del globo ocular, se debe establecer un diagnóstico oportuno y un tratamiento adecuado para disminuir el riesgo de desenlaces graves e irreversibles. Es imperativo la realización de más estudios que evalúen la implementación y aplicabilidad de los tratamientos descritos, especialmente de voriconazol dado su espectro de acción, seguridad y preferencia por parte de médicos oftalmólo-

\section{Tabla 3. Terapia médica recomendada para la queratitis fúngica}

\begin{tabular}{ll}
\hline Microorganismo & \multicolumn{1}{c}{$\begin{array}{c}\text { Tratamiento médico tópico } \\
\text { recomendado según acceso* }\end{array}$} \\
\hline Hongos filamentosos & 10 Voriconazol 1\% \\
& 20 Natamicina $5 \%$ \\
Levaduras & 10 Voriconazol $1 \%$ \\
& 20 Anfotericina 0,15\% (1,5 mg/1 mL) \\
Desconocido & 10 Voriconazol 1\%+Anfotericina 0,15\% \\
& 20 Anfotericina 0,15\%+Natamicina 5\% \\
\hline
\end{tabular}

* = se recomienda la administración antibiótica cada 1 hora inicialmente, acompañada de debridaciones cada 3 días. La aplicación tópica se distanciará según mejoría clínica. Si no se logra mejoría típica temprana debe derivarse a especialista en córnea para eventual resolución quirúrgica.

Tabla 4. Terapia médica sistémica coadyuvante en casos de queratitis fúngica severa*

\begin{tabular}{lc}
\hline Microorganismo & \multicolumn{1}{c}{$\begin{array}{c}\text { Tratamiento médico sistémico } \\
\text { recomendado según acceso* }\end{array}$} \\
\hline Hongos filamentosos & $\begin{array}{l}\text { 10 Voriconazol oral } 400 \mathrm{mg} / \mathrm{d} \\
\text { 2o Itraconazol oral } 100-200 \mathrm{mg} \text { cada } 12 \mathrm{hrs}\end{array}$ \\
& 10 Voriconazol oral $400 \mathrm{mg} / \mathrm{d}$ \\
Levaduras & Anfotericina intracameral $(5 \mathrm{mcg} / 0,05 \mathrm{~mL}$ agua estéril) \\
& Voriconazol intracameral $(50 \mathrm{mcg} / 0,05 \mathrm{~mL}$ agua estéril) \\
& 3 Fluconazol oral $400 \mathrm{mg} / \mathrm{d}$ \\
\hline
\end{tabular}

* = se recomienda la administración antibiótica sistémica coadyuvante al tratamiento tópico, en casos de compromiso de cámara anterior, úlceras grandes y profundas, compromiso de cámara anterior y falla a tratamiento tópico inicial con germen identificado. 
gos a nivel mundial. Se debe evaluar el costo-beneficio terapéutico, para que independiente de los recursos económicos de un sistema de salud, éstos apunten a garantizar la terapia de mejor efectividad demostrada y que mayor beneficio reporte para el paciente.

\section{REFERENCIAS}

1. Whitcher JP, Srinivasan M, Upadhyay MP. Corneal blindness: a global perspective. Bull World Health Organ [Internet]. 2001[cited 2012 Feb 21];79(3):214-21. Available from: http://www.scielosp.org/pdf/bwho/v79n3/v79n3a09.pdf

2. Passos RM, Cariello AJ, Yu MC, Höfling-Lima AL. Microbial keratitis in the elderly: a 32-year review. Arq Bras Oftalmol [Internet] 2010[cited 2011 Oct 21];73:315-9. Available from: http://www.scielo.br/pdf/abo/v73n4/v73n4a02.pdf

3. Liesegang TJ, Forster RK. Spectrum of microbial keratitis in South Florida. Am J Ophthalmol 1980;90(1):38-47.

4. Gopinathan U, Sharma S, Garg P, Rao GN. Review of epidemiological features, microbiological diagnosis and treatment outcome of microbial keratitis: experience of over a decade. Indian J Ophthalmol [Internet]. 2009[cited 2010 Nov 7];57(4):273-9. Available from: http://www.ncbi.n/m.nih.gov/pmc/articles/PMC2712695/

5. Furlanetto RL, Andreo EG, Finotti IG, Arcieri ES, Ferreira MA, Rocha FJ. Epidemiology and etiologic diagnosis of infectious keratitis in Uberlandia, Brazil. Eur J Ophthalmol. 2010;20(3):498-503.

6. Ibrahim MM, Vanini R, Ibrahim FM, Fioriti LS, Furlan EM, Provinzano LM, De Castro RS, Sousa SJ, Rocha EM. Epidemiologic aspects and clinical outcome of fungal keratitis in southeastern Brazil. Eur J Ophthalmol. 2009;19:355-61.

7. Iyer SA, Tuli SS, Wagoner RC. Fungal keratitis: emerging trends and treatment outcomes. Eye Contact Lens. 2006;32(6):267-71.

8. Gower EW, Keay L, Oechsler RA, lovieno A, Alfonso EC, Jones CD, et al. Trends in fungal keratitis in the United States, 2001 to 2007. Ophthalmology [Internet]. 2010[cited 2012 Jun 21];117(12):2263-7. Available from: http://ac.els-cdn.com/S0161642010003271/ 1-s2.0-S0161642010003271-main.pdf?_tid=4862006e-8be0-11e2-a772-00000aab0f6c \&acdnat=1363180797_2793943d9323cfa131ce51f00ce4a86d

9. Nicola F. [Non-viral infectious keratitis: predisposing factors, etiologic agents and laboratory diagnosis]. Rev Argent Microbiol. 2005;37(4):229-39. Spanish.

10. Miño de Kaspar H, Zoulek G, Paredes ME, Alborno R, Medina D, Centurion de Morinigo M, et al. Mycotic keratitis in Paraguay. Mycoses. 1991;34:251-4.

11. Jurkunas U, Behlau I, Colby K. Fungal keratitis: changing pathogens and risk factors. Cornea. 2009;28(6):638-43.

12. Yildiz EH, Abdalla YF, Elsahn AF, Rapuano CJ, Hammersmith KM, Laibson PR, et al. Update on fungal keratitis from 1999 to 2008. Cornea. 2010;29(12):1406-11.

13. O'Day DM, Head WS, Robinson RD, Clanton JA. Corneal penetration of topical amphotericin B and natamycin. Curr Eye Res. 1986;5(11):877-82.

14. Tuli SS. Fungal keratitis. Clin Ophthalmol[Internet]. 2011 [cited 2012 Aug 25];5:275-9. Available from: http://www.ncbi.n/m.nih.gov/pmc/articles/PMC3065567/

15. Loh AR, Hong K, Lee S, Mannis M, Acharya NR. Practice patterns in the management of fungal corneal ulcers. Cornea. 2009;28:856-9.

16. Thomas PA, Leck AK, Myatt M. Characteristic clinical features as an aid to the diagnosis of suppurative keratitis caused by filamentous fungi. Br J Ophthalmol [Internet. 2005[cited 2011 Oct 23];89:1554-8. Available from: http://www.ncbi.nlm.nih.gov/ pmc/articles/PMC1772991/

17. Ibrahim MM, Vanini R, Ibrahim FM, Fioriti LS, Furlan EM, Provinzano LM, et al. Epidemiologic aspects and clinical outcome of fungal keratitis in southeastern Brazil. Eur J Ophthalmol. 2009;19(3):355-61.

18. Chang HY, Chodosh J. Diagnostic and therapeutic considerations in fungal keratitis. Int Ophthalmol Clin. 2011;51(4):33-42.

19. Badiee P, Nejabat M, Alborzi A, Keshavarz F, Shakiba E. Comparative study of gram stain, potassium hydroxide smear, culture and nested PCR in the diagnosis of fungal keratitis. Ophthalmic Res [Internet]. 2010[cited 2012 May 21];44(4):251-6. Available from: http://www.karger.com/Article/FullText/313988

20. Bharathi MJ, Ramakrishnan R, Meenakshi R, Mittal S, Shivakumar C, Srinivasan M. Microbiological diagnosis of infective keratitis: comparative evaluation of direct microscopy and culture results. Br J Ophthalmol [Internet]. 2006[cited 2010 Aug 21];90:1271-6. Available from: http://bjo.bmj.com/content/90/10/1271.long

21. Vengayil S, Panda A, Satpathy G, Nayak N, Ghose S, Patanaik D, et al. Polymerase chain reaction-guided diagnosis of mycotic keratitis: a prospective evaluation of its efficacy and limitations. Invest Ophthalmol Vis Sci [Internet]. 2009 [cited 2012 Dec 21];50(1):152-6. Available from: http://www.iovs.org/content/50/1/152.long

22. Victor G, Alves MR, Nosé W. Microscopia confocal in vivo no diagnóstico de ceratite fúngica: relato de caso. Arq Bras Oftalmol [Internet]. 2006[citado 2011 Fev 12]; 69;399-402. Disponível em: http://www.scielo.br/pdf/abo/v69n3/30794.pdf
23. Vaddavalli PK, Garg P, Sharma S, Sangwan VS, Rao GN, Thomas R. Role of confocal microscopy in the diagnosis of fungal and acanthamoeba keratitis. Ophthalmology [Internet]. 2011[cited 2012 May 24];118(1):29-35. Comment in: Ophthalmology. 2012;119(2):428-9; author reply 429-30. Available from: http://linkinghub.elsevier. com/retrieve/pii/S0161-6420(10)00560-9

24. Natamycin approved-first US drug for fungal keratitis. FDA Drug Bull. 1978;8(6):37-8

25. Hariprasad SM, Mieler WF, Lin TK, Sponsel WE, Graybill JR. Voriconazole in the treatment of fungal eye infections: a review of current literature. Br J Ophthalmol. 2008; 92(7):871-8.

26. Agarwal PK, Roy P, Das A, Banerjee A, Maity PK, Banerjee AR. Efficacy of topical and systemic itraconazole as a broad-spectrum antifungal agent in mycotic corneal ulcer. A preliminary study. Indian J Ophthalmol [Internet]. 2001[cited 2010 Mar 19]; 49(3):173-6. Comment in: Indian J Opthalmol. 2002;50(1):71-2; author reply 72 Available from: http://www.ijo.in/article.asp?issn=0301-4738; year $=2001$; volume $=49$; issue $=3$; page $=173 ;$ epage $=176$; aulast $=$ Agarwal

27. Parchand S, Gupta A, Ram J, Gupta N, Chakrabarty A. Voriconazole for fungal cornea ulcers. Ophthalmology [Internet]. 2012[cited 2012 Dec 21];119(5):1083. Available from: http://www.sciencedirect.com/science/article/pii/S0161642011011407

28. Bennett JE. Diagnosis and treatment of fungal infections. In: Fauci AS, Braunwald $E_{,}$ Isselbacher KJ, Wilson JD, Martin IB, Kasper DL, et al, editors. Harrison's principles of Internal Medicine. 14th ed. New York: McGraw - Hill; 1998. v. 1, p.1148-54.

29. Marangon FB, Miller D, Giaconi JA, et al. In vitro investigation of voriconazole susceptibility for keratitis and endophthalmitis fungal pathogens. Am J ophthalmol [Internet]. 2004 [cited 2011 Aug 4];137(5):820-5. Available from: http://www.sciencedirect.com/ science/article/pii/S0002939403015265

30. Shen YC, Wang CY, Tsai HY, Lee HN, Intracameral voriconazole injection in the treatment of fungal endophtalmitis resulting from keratitis. Am J Ophthalmol [Internet]. 2010 [cited 2012 Oct 21];149(6);916-21. Comment in: Am J Ophthalmol. 2010;150(6):939; author reply 939-40; Am J Ophthalmol. 2011;151(1):185-6; author reply 186. Available from: http://www.sciencedirect.com/science/article/pii/S0002939410000668

31. Lin RC, Sanduja N, Hariprasad SM. Succesful treatment of postoperative fungal endophthalmitis using intravitreal and intracameral voriconazole. J Ocul Pharmacol Ther [Internet]. 2008[cited 2010 Apr 21];24(2):245-8. Available from: http://online. liebertpub.com/doi/pdf/10.1089/jop.2007.0105

32. Carrasco MA, Genesoni G. Treatment of severe fungal keratitis with subconjunctival amphotericin B. Cornea. 2011;30(5);608-11.

33. Chen WL, Wu CY, Hu FR, Wang IJ. Therapeutic penetrating keratoplasty for microbial keratitis in Taiwan from 1987-2001. Am. J Ophthalmol [Internet] 2004[cited $2010 \mathrm{Mar}$ 23];137(4):736-43.Available from: http://www.sciencedirect.com/science/article/pii/ S000293940301417X

34. Foster CS, Lass JH, Moran-Wallace K, Giovanoni R. Ocular toxicity of topical antifungal agents. Arch Ophthalmol.1981;99(6):1081-4

35. Oliveira PR de, Resende SM, Oliveira FC de, Oliveira AC de. Ceratite fúngica. Arq Bras Oftalmol [Internet]. 2001[citado 2010 Jan 21];64(1);75-9. Disponível em: http://www. scielo.br/pdf/abo/v64n1/9130.pdf

36. Forster RK, Rebell G. Therapeutic surgery in failures of medical treatment for funga keratitis. Br J Ophthalmol [Internet]. 1975[cited 2010 Jun 21];59(7):366-71.Available from: http://bjo.bmj.com/content/59/7/366.long

37. Shi W, Wang T, Xie L, Li S, Gao H, Liu J, al. Risk factors, clinical features, and outcomes of recurrent fungal keratitis after corneal transplantation. Ophthalmology [Internet]. 2010[cited 2011 Jun 12];1 17(5);890-6. Available from: http://www.sciencedirect.com/ science/article/pii/S0161642009011750

38. Galperin G, Berra M, Tau J, Boscaro G, Zarate J, Berra A. Treatment of fungal keratitis from Fusarium infection by corneal cross-linking. Cornea. 2012;31(2);176-80. Comment in: Cornea. 2013;32(2):218; Cornea. 2013;32(2):217-8.

39. Florcruz NV, Peczon I Jr. Medical interventions for fungal keratitis. Cochrane Database Syst Rev 2008:23(1):CD004241.

40. Mahdy RA, Nada WM, Wageh MM. Topical amphotericin B and subconjunctival injection of fluconazole (combination therapy) versus topical amphotericin B (monotherapy) in treatment of keratomycosis. J Ocul Pharmacol Ther [Internet]. 2010[cited 2012 Jul 21];26(3):281-5. Available from: http://online.liebertpub.com/doi/ pdf/10.1089/jop.2010.0005

41. Prajna NV, Mascarenhas J, Krishnan T, Reddy PR, Prajna L, Srinivasan M, et al. Comparison of natamycin and voriconazole for the treatment of fungal keratitis. Arch Ophthalmol [Internet]. 2010[cited 2012 Apr 21];128:672-8. Comment in: Arch Ophthalmol. 2011;129(6):814; author reply 814-5. Available from: http://archopht. jamanetwork.com/article.aspx?articleid $=425787$

42. Arora R, Gupta D, Goyal J, Kaur R. Voriconazole versus natamycin as primary treatment in fungal corneal ulcers. Clin Experiment Ophthalmol [Internet]. 2011 [cited 2012 Jul 27];39(5):434-40. Available from: http://onlinelibrary.wiley.com/doi/10.1111/j. 1442-9071.2010.02473.x/full 